\title{
Problèmes actuels en Allemagne - Introduction
}

\section{Wolfgang Brücher}

\section{OpenEdition}

\section{Journals}

Édition électronique

URL : http://journals.openedition.org/rge/3829

DOI : $10.4000 /$ rge.3829

ISSN : 2108-6478

\section{Éditeur}

Association des géographes de l'Est

\section{Édition imprimée}

Date de publication : 1 janvier 2001

ISSN : 0035-3213

\section{Référence électronique}

Wolfgang Brücher, "Problèmes actuels en Allemagne - Introduction », Revue Géographique de l'Est [En ligne], vol. 41 / 1-2 | 2001, mis en ligne le 10 juillet 2013, consulté le 22 septembre 2020. URL : http:// journals.openedition.org/rge/3829; DOI : https://doi.org/10.4000/rge.3829

Ce document a été généré automatiquement le 22 septembre 2020

Tous droits réservés 


\title{
Problèmes actuels en Allemagne - Introduction
}

\author{
Wolfgang Brücher
}

1 Lorsque le comité de rédaction de la RGE a décidé de consacrer un cahier entier à l'Allemagne, il a d'abord été question de lui donner comme "leitmotiv» les conséquences de la réunification en 1989/1990. En effet, depuis la douzaine d'années écoulées depuis la chute du mur de Berlin et, ensuite, la disparition du socialisme en Europe de l'Est, le pays a connu des changements plus profonds, plus complexes et plus rapides que jamais depuis la Deuxième Guerre mondiale, sans même parler ici de ses nouvelles structure et situation proprement politiques. Pourtant, les changements qui sont loin d'être terminés ne dérivent pas exclusivement de ces événements bouleversants que personne n'aurait pu prévoir. Car en même temps, notre pays, comme tous les autres, a subi également l'impact de facteurs globaux comme, par exemple, la mondialisation elle-même, l'intensification des relations européennes, la révolution des transports et de l'information, l'augmentation des migrations ou la dégradation de l'environnement. Justement, de telles influences ne peuvent pas être dissociées ni vues séparément de la nouvelle situation du pays, ni de sa nouvelle position en Europe et dans le monde : si, comparé à l'ancienne Allemagne de l'Ouest, il a gagné en poids politique, il se voit désormais chargé de bien plus de problèmes socioéconomiques intérieurs et de nouvelles responsabilités internationales, ne pouvant plus s'enfermer derrière la paroi de son statut spécial d'antan.

2 Ainsi, nous préférons le titre plus neutre, plus réaliste de "problèmes actuels en Allemagne », tout en sachant que dans l'espace limité de cette édition de la RGE, nous ne pouvons présenter que quelques exemples de ce qui nous semble être représentatif de l'actualité. Mais pour qu'il n'en résulte pas un tableau trop partial, vu par des autochtones on a cherché la coopération d'auteurs des deux côtés de la frontière. Evidemment, il faut prêter une attention spéciale à la situation de l'Allemagne de l'Est qui subit les changements les plus profonds, brutaux même sous certains aspects. Elle est observée dans une perspective plutôt extravagante, vu la diversité des auteurs : la réhabilitation du paysage d'anciennes mines est décrite par un géomorphologue de 
Nancy, Michel Deshaies; l'industrie en Thuringe est présentée par Peter Sedlacek, enseignant à Iéna, mais originaire de l'ouest, et nous voyons Berlin (Bärbel Leupolt et Jean-François Machon) à travers les yeux d'une Berlinoise authentique, mais enseignant à Hambourg, en collaboration avec un Français vivant au bord de la Spree. C'est également un couple d'auteurs franco-allemand, Etienne Auphan (Paris) et Konrad Schliephake (Würzburg), qui met en relief les impacts de la réunification sur la reconstruction, ou plutôt sur la nouvelle conception du réseau ferré déchiré jusque-là par le rideau de fer. Que ce cahier comprenne aussi un article sur les mutations dans le secteur de l'électricité, à l'exemple individuel de la Sarre, devrait étonner le lecteur français trop habitué au monolithisme stable de l'EDF, mais l'équipe de Sarrebruck (Wolfgang Brücher, Peter Dörrenbächer, Malte Helfer et Nicolai Zwosta) y voit un sujet de haute actualité qui reflète bien la transformation importante sur le plan fédéral de cette partie de l'économie (malheureusement assez négligée par les géographes). Il n'est certainement pas moins étonnant de trouver ici un article (Britta Klagge, Hambourg) sur la pauvreté en Allemagne, phénomène qui y existe pourtant comme dans tous les pays industrialisés et qualifiés de « riches ». Nous terminons avec un sujet encore plus "typiquement allemand", la réglementation trop rigide des heures de fermeture des magasins (Günter Heinritz, Munich) qui n'a jamais été bien comprise ni par les étrangers en visite ni par les Allemands eux-mêmes. Sa flexibilisation en cours ne montre-t-elle pas plus que d'autres indices plus spectaculaires que l'Allemagne est en train de changer sérieusement?

\section{AUTEUR}

\section{WOLFGANG BRÜCHER}

Fachrichtung Geographie - Universität des Saarlandes - D.66041 - Saarbrücken 